\title{
Цифровая экономика и показатели качества жизни
}

\author{
О.В. Александров \\ ЦЭФК Групп \\ aleksandrov@cefc.ru
}

\section{Аннотация}

Реализация новых международных инициатив по выработке современных инструментов статистического измерения устойчивого развития общества приводит к необходимости развития методологии и информационных источников для формирования показателей качества жизни населения. В данной статье автор анализирует состав показателей целей устойчивого развития ООН, действующие источники и методологию сбора данных и предлагает использовать данные обследований в социальных сетях, данные действующих реестров и регистров, а также альтернативные источники данных о ценах товаров, включаемых в потребительскую корзину, для измерения ряда показателей целей устойчивого развития ООН по России.

Ключевые слова: цели устойчивого развития, бедность, социальные сети, показатели

Библиографическая ссылка: Александров О.В. Цифровая экономика и показатели качества жизни // Государство и граждане в электронной среде. Выпуск 3 (Труды XXII Международной объединенной научной конференции «Интернет и современное общество», IMS-2019, Санкт-Петербург, 19-22 июня 2019 г. Сборник научных трудов). - СПб: Университет ИТМО, 2019. С. 25 - 34. DOI: 10.17586/2541-979Х2019-3-25-34

В 2015 году государствами-членами ООН принята Программа устойчивого развития на период до 2030 года, содержащая 17 целей (ЦУР) [1]. В 2017 году Генеральной Ассамблеей $\mathrm{OOH}$ был принят окончательный список из 230 показателей, которые конкретизируют каждую из 169 задач ЦУР. Важная роль в достижении ЦУР принадлежит новым и эффективным способам сбора данных, мониторинга целей и измерения прогресса. В соответствии с принятыми международными стандартами обмена статистическими данными распоряжением Правительства Российской Федерации от 6 июня 2017 года №1170-p Росстату поручено обеспечить координацию деятельности субъектов статистического учета по формированию и представлению в международные организации официальной статистической информации по Показателям мониторинга достижения ЦУР по Российской Федерации. Распоряжением Правительства Российской Федерации от 23 сентября 2017 года № 2033-р в Федеральный план статистических работ включен перечень дополнительной официальной статистической информации по показателям достижения целей устойчивого развития Российской Федерации.

Возложенные на Россию задачи внедрения в практику измерения показателей мониторинга ЦУР диктуют необходимость определения наиболее рациональных и оптимальных условий получения дополнительной эмпирической базы, используемой для формирования показателей ЦУР, в том числе в соответствии с методологией международных организаций, определенных Статкомиссией ООН «организациямикоординаторами», уполномоченными нести ответственность за сбор данных из национальных источников. 
В качестве информационной базы для расчета показателей ЦУР в Российской Федерации определена система выборочных наблюдений по социально-демографическим проблемам, реализуемая органами государственной статистики ежегодно, начиная с 2011 года. Система выборочных обследований представляет собой серию периодических опросов, охватывающих различные сферы жизнедеятельности российских домашних хозяйств и представляющих итоговую информацию как по населению в целом, так и в разбивке по полу, возрасту, доходу, месту проживания, роду занятий и другим аспектам социальной идентичности.

Информационная база, формируемая по итогам выборочных наблюдений по социально-демографическим проблемам, призвана обеспечивать мониторинг ЦУР в области неравенства и бедности, социальной защиты, неполноценного питания, здорового образа жизни и условий проживания и применима к следующим показателям ЦУР:

- (1.1.1) Доля населения, живущего за международной чертой бедности, в разбивке по полу, возрасту, статусу занятости и месту проживания (городское/ сельское);

- (1.2.1) Доля населения страны, живущего за национальной чертой бедности, в разбивке по полу и возрасту;

- (1.2.2) Доля мужчин, женщин и детей всех возрастов, живущих в нищете во всех ее проявлениях, согласно национальным определениям;

- (1.3.1) Доля населения, охватываемого минимальным уровнем/ системами социальной защиты, в разбивке по полу, с выделением детей, безработных, пожилых, инвалидов, беременных, новорожденных, лиц, получивших трудовое увечье, бедных и уязвимых;

- (1.4.2) Доля совокупного взрослого населения, обладающего гарантированными правами землевладения, которые подтверждены признанными законом документами, и считающего свои права на землю гарантированными, в разбивке по полу и по формам землевладения;

- (2.1.1) Распространенность недоедания;

- (2.1.2) Уровень умеренного или острого отсутствия продовольственной безопасности населения, по Шкале восприятия отсутствия продовольственной безопасности;

- (2.2.1) Распространенность задержки роста среди детей в возрасте до пяти лет (среднеквадратичное отклонение от медианного показателя роста к возрасту ребенка в соответствии с нормами роста детей, установленными Всемирной организацией здравоохранения (ВО3), <-2);

- (2.2.2) Распространенность неполноценного питания среди детей в возрасте до пяти лет в разбивке по виду (истощение или ожирение) (среднеквадратичное отклонение от медианного показателя веса к возрасту в соответствии с нормами роста детей, установленными ВО3, >+2 или <-2);

- (3.а.1) Стандартизированная по возрасту распространенность употребления табака лицами в возрасте от 15 лет;

- (5.4.1) Доля времени, затрачиваемого на неоплачиваемый труд по уходу и работу по дому, в разбивке по полу, возрасту и месту проживания;

- (6.1.1) Доля населения, пользующегося услугами водоснабжения, организованного с соблюдением требований безопасности;

- (6.2.1) Доля населения, использующего организованные с соблюдением требований безопасности услуги санитарии, включая устройства для мытья рук с мылом и водой;

- (7.1.1) Доля населения, имеющего доступ к электроэнергии;

- (8.7.1) Доля и число детей в возрасте от 5 до 17 лет, занятых детским трудом, в разбивке по полу и возрасту;

- (10.1.1) Темпы роста расходов домохозяйств или доходов на душу населения среди наименее обеспеченных 40 процентов населения и среди населения в целом;

- (11.2.1) Доля населения, имеющего удобный доступ к общественному транспорту, в разбивке по полу, возрасту и признаку инвалидности. 
Международными организациями-координаторами по вопросам разработки методологии формирования показателей ЦУР (далее - международные организациикоординаторы показателей ЦУР) в соответствующих областях являются: Всемирный банк (World Bank) [2]; Международная организация труда (ILO) [3]; Программа OOH по населенным пунктам (UN-Habitat); Управление $\mathrm{OOH}$ по вопросам уменьшения опасности стихийных бедствий (UNISDR); Международный чрезвычайный детский фонд $\mathrm{OOH}$ (UNICEF); Продовольственная и сельскохозяйственная организация ООН (FAO) [4]; Организация экономического сотрудничества и развития (OECD); Структура ОOH по вопросам гендерного равенства и расширения прав и возможностей женщин (UN Women); Международный союз электросвязи (ITU); Всемирный почтовый союз(UPU); Программа $\mathrm{OOH}$ по окружающей среде (UNEP); Международный фонд сельскохозяйственного развития (IFAD); Отдел народонаселения ООН (DESA Population Division); OOH по вопросам образования, науки и культуры (UNESCO); Программа развития OOH (UNDP); Фонд ООН в области народонаселения (UNFPA); Всемирная организация здравоохранения (WHO) [5]; Целевая группа ОOН по энергетике (UN-Energy).

Распределение ответственности по вопросам разработки методологии формирования показателей ЦУР представлено в табл. 1.

Таблица 1. Распределение ответственности по вопросам разработки методологии формирования показателей Целей в области устойчивого развития

\begin{tabular}{|c|c|c|}
\hline Показатель & $\begin{array}{c}\text { Международная } \\
\text { организация }\end{array}$ & $\begin{array}{c}\text { Организация- } \\
\text { партнер }\end{array}$ \\
\hline $\begin{array}{l}\text { (1.1.1) Доля населения, живущего за международной } \\
\text { чертой бедности, в разбивке по полу, возрасту, } \\
\text { статусу занятости и месту проживания (городское/ } \\
\text { сельское) } \\
\text { (1.2.1) Доля населения страны, живущего за } \\
\text { национальной чертой бедности, в разбивке по полу и } \\
\text { возрасту } \\
\text { (1.2.2) Доля мужчин, женщин и детей всех возрастов, } \\
\text { живущих в нищете во всех ее проявлениях, согласно } \\
\text { национальным определениям } \\
\text { (1.3.1) Доля населения, охватываемого минимальным } \\
\text { уровнем/ системами социальной защиты, в разбивке } \\
\text { по полу, с выделением детей, безработных, пожилых, } \\
\text { инвалидов, беременных, новорожденных, лиц, } \\
\text { получивших трудовое увечье, бедных и уязвимых } \\
\text { (1.4.2) Доля совокупного взрослого населения, } \\
\text { обладающего гарантированными правами } \\
\text { землевладения, которые подтверждены признанными } \\
\text { законом документами, и считающего свои права на } \\
\text { землю гарантированными, в разбивке по полу и по } \\
\text { формам землевладения } \\
\text { (2.1.1) Распространенность недоедания } \\
\text { (2.1.2) Уровень умеренного или острого отсутствия } \\
\text { продовольственной безопасности населения, по } \\
\text { Шкале восприятия отсутствия продовольственной } \\
\text { безопасности } \\
\text { (2.2.1) Распространенность задержки роста среди } \\
\text { детей в возрасте до пяти лет (среднеквадратичное } \\
\text { отклонение от медианного показателя роста к } \\
\text { возрасту ребенка в соответствии с нормами роста } \\
\text { детей, установленными Всемирной организацией } \\
\text { здравоохранения (ВОЗ), <-2) }\end{array}$ & $\begin{array}{l}\text { World Bank, UN- } \\
\text { Habitat } \\
\text { FAO [4] } \\
\text { FAO [4] }\end{array}$ & $\begin{array}{l}\text { UNICEF } \\
\text { UNICEF, } \\
\text { World Bank, } \\
\text { UNDP } \\
\text { World Bank [2] }\end{array}$ \\
\hline
\end{tabular}




\begin{tabular}{|c|c|c|}
\hline Показатель & $\begin{array}{c}\text { Международная } \\
\text { организация }\end{array}$ & $\begin{array}{c}\text { Организация- } \\
\text { партнер }\end{array}$ \\
\hline $\begin{array}{l}\text { (2.2.2) Распространенность неполноценного питания } \\
\text { среди детей в возрасте до пяти лет в разбивке по виду } \\
\text { (истощение или ожирение) (среднеквадратичное } \\
\text { отклонение от медианного показателя веса к возрасту } \\
\text { в соответствии с нормами роста детей, } \\
\text { установленными ВОЗ, >+2 или <-2) } \\
\text { (3.а.1) Стандартизированная по возрасту } \\
\text { распространенность употребления табака лицами в } \\
\text { возрасте от } 15 \text { лет } \\
\text { (5.4.1) Доля времени, затрачиваемого на } \\
\text { неоплачивамый труд по уходу и работу по дому, в } \\
\text { разбивке по полу, возрасту и месту проживания } \\
\text { (6.1.1) Доля населения, пользующегося услугами } \\
\text { водоснабжения, организованного с соблюдением } \\
\text { требований безопасности } \\
\text { (6.2.1) Доля населения, использующего } \\
\text { организованные с соблюдением требований } \\
\text { безопасности услуги санитарии, включая устройства } \\
\text { для мытья рук с мылом и водой } \\
\text { (7.1.1) Доля населения, имеющего доступ к } \\
\text { электроэнергии } \\
\text { (8.7.1) Доля и число детей в возрасте от } 5 \text { до } 17 \text { лет, } \\
\text { занятых детским трудом, в разбивке по полу и } \\
\text { возрасту } \\
\text { (10.1.1) Темпы роста расходов домохозяйств или } \\
\text { доходов на душу населения среди наименее } \\
\text { обеспеченных } 40 \text { процентов населения и среди } \\
\text { населения в целом } \\
\text { (11.2.1) Доля населения, имеющего удобный доступ к } \\
\text { общественному транспорту, в разбивке по полу, } \\
\text { возрасту и признаку инвалидности. }\end{array}$ & $\begin{array}{c}\text { WHO, WHO-FCTC } \\
\text { UNSD } \\
\text { UN Women } \\
\text { WHO, UNICEF }\end{array}$ & $\begin{array}{c}\text { UNEP, } \\
\text { UN-Habitat } \\
\text { UNEP } \\
\text { IEA, } \\
\text { UN-Energy }\end{array}$ \\
\hline
\end{tabular}

Bсе указанные показатели распределяются по уровням, в зависимости от концептуальной ясности, методологии и наличии стандартов и данных в отношении показателей ЦУР:

Уровень 1: Показатель является концептуально ясным, имеет международнопризнанную методологию и стандарты, страны регулярно готовят данные (по меньшей мере по 50\% процентам стран и населения в каждом регионе, где этот показатель является актуальным).

Уровень 2: Показатель концептуально ясен, имеет международно-устоявшуюся методологию и стандарты, но данные готовятся странами нерегулярно.

Уровень 3: Показатель, по которому не существует международной методологии или стандартов, однако методология/стандарты разрабатываются (или будут разрабатываться) или будут апробироваться.

Большая часть из указанных показателей относится к 1 уровню (они концептуально ясны, имеют международно-признанную методологию и стандарты, а страны регулярно готовят данные по этим показателям).

Однако в этом перечне есть один показатель 3 уровня, по которому не существует международной методологии или стандартов, однако методология/стандарты разрабатываются - показатель 1.4.2 (доля совокупного взрослого населения, обладающего гарантированными правами землевладения, которые подтверждены признанными законом документами, и считающего свои права на землю гарантированными, в разбивке по полу и по формам землевладения). Вместе с тем, за последние годы в России сформирован 
Единый реестр недвижимости (далее - ЕГРН), в который входят в том числе данные о правах физических лиц на земельные участки (в разбивке по РФ, субъектам РФ, конкретным физическим лицам, назначению использования земли и формам владения земельными участками). Таким образом, данные по этому показателю ЦУР можно получать напрямую из имеющегося источника первичных данных - ЕГРН, не проводя дополнительных выборочных исследований и наблюдений.

Показатели 1.2.2 (Доля мужчин, женщин и детей всех возрастов, живущих в нищете во всех ее проявлениях, согласно национальным определениям), 1.3.1 (Доля населения, охватываемого минимальным уровнем/ системами социальной защиты, в разбивке по полу, с выделением детей, безработных, пожилых, инвалидов, беременных, новорожденных, лиц, получивших трудовое увечье, бедных и уязвимых), 5.4.1. (Доля времени, затрачиваемого на неоплачиваемый труд по уходу и работу по дому, в разбивке по полу, возрасту и месту проживания) и 11.2.1. (Доля населения, имеющего удобный доступ к общественному транспорту, в разбивке по полу, возрасту и признаку инвалидности) относятся ко 2 уровню.

Ряд этих показателей концептуально ясны, имеют международно-устоявшуюся методологию и стандарты. Однако появившиеся в последние годы новые источники информации, позволяют пересмотреть подходы к получению данных по этим показателям и сформировать новую методологию измерения соответствующих этим показателям целей устойчивого развития ООН, в том числе по России.

В частности, предлагается разработать и апробировать новую методологию для совершенствования эмпирической базы, обеспечивающей внедрение в статистическую практику показателей Целей устойчивого развития по населению в целом и по отдельным группам населения.

Для формирования новой методологии необходимо в первую очередь систематизировать материалы по действующим методам формирования показателей, обеспечивающих мониторинг Целей устойчивого развития в области неравенства и бедности, социальной защиты, неполноценного питания, здорового образа жизни и условий проживания, приведенные в методологии международных организаций организаций-координаторов показателей ЦУР.

По результатам этой работы возможно сформировать базу данных с итогами обобщения материалов по каждому показателю ЦУР и соответствующей действующей методологии сбора данных, необходимых для его расчета и принятых в соответствующей международной организации.

Далее необходимо проанализировать имеющуюся в Росстате эмпирическую базу по данным вопросам, в том числе проанализировать нормативные правовые и методологические документы, а также совокупности данных по итогам выборочного наблюдения доходов населения и участия в социальных программах, комплексного обследования условий жизни населения, выборочного наблюдения рациона питания населения, выборочного наблюдения использования суточного фонда времени населением, которые проводятся Росстатом на регулярной основе.

Как уже отмечалось выше, эмпирической базой, имеющейся в Росстате и обеспечивающей внедрение в статистическую практику показателей ЦУР по населению в целом и по отдельным группам населения, в настоящее время являются [6]:

- выборочное наблюдение доходов населения и участия в социальных программах;

- комплексное обследование условий жизни населения;

- выборочное наблюдение рациона питания населения;

- выборочное наблюдение использования суточного фонда времени населением.

Предварительный анализ методологии данных имеющейся эмпирической базы показывает, что для целей сбора данных по показателям ЦУР, ее использование в России представляет определенные затруднения и она нуждается в совершенствовании. 
Например, в совершенствовании методологии сбора данных нуждаются следующие показатели Цели устойчивого развития №1 (Ликвидация нищеты во всех ее формах в мире):

- показатель 1.1.1 Доля населения, живущего за международной чертой бедности, в разбивке по полу, возрасту, статусу занятости и месту проживания (городское/ сельское);

- показатель 1.2.1. Доля населения страны, живущего за национальной чертой бедности, в разбивке по полу и возрасту;

- показатель 1.2.2. Доля мужчин, женщин и детей всех возрастов, живущих в нищете во всех ее проявлениях, согласно национальным определениям;

- показатель 1.3.1. Доля населения, охватываемого минимальным уровнем/ системами социальной защиты, в разбивке по полу, с выделением детей, безработных, пожилых, инвалидов, беременных, новорожденных, лиц, получивших трудовое увечье, бедных и уязвимых;

- показатель 1.4.2. Доля совокупного взрослого населения, обладающего гарантированными правами землевладения, которые подтверждены признанными законом документами, и считающего свои права на землю гарантированными, в разбивке по полу и по формам землевладения.

В качестве основной эмпирической базы для части этих показателей (1.1.1., 1.2.1., 1.2.2. и 1.3.1.) в настоящее время используется «Выборочное наблюдение доходов населения и участия в социальных программах».

Задачей проведения этого наблюдения является получение статистических данных о денежных и совокупных доходах домохозяйств, о видах доходных источников и количестве получателей доходов в семьях, об условиях получения и размерах доходов от работы по найму, самостоятельной занятости (включая личные подсобные хозяйства), о среднемесячном доходе от трудовой деятельности, об объемах натуральных поступлений товаров и услуг собственного производства в денежном эквиваленте, о видах и размерах назначенных пенсий и социальных пособий, страховых возмещениях и вкладе в добровольное страхование, о размерах доходов от участия в программах семейных пособий и социальной защиты, о наличии доходов от собственности, об объемах межсемейной помощи, о выплаченных налогах и налоговых льготах.

Данное Выборочное наблюдение в настоящее время осуществляется в соответствии с Постановлением Правительства РФ от 27 ноября 2010 г. № 946 «Об организации в Российской Федерации системы федеральных статистических наблюдений по социальнодемографическим проблемам и мониторинга экономических потерь от смертности, заболеваемости и инвалидизации населения» [7], Порядком агрегирования компонентов доходов, наблюдаемых в программе выборочного наблюдения доходов населения и участия в социальных программах, в показатели общего объема денежных (совокупных) доходов, Основными методологическими и организационными положениями Выборочного наблюдения доходов населения и участия в социальных программах в 2017 году и Указаниями по подготовке и проведению Выборочного наблюдения доходов населения и участия в социальных программах в 2017 году.

Необходимо отметить, что Указаниями по подготовке и проведению Выборочного наблюдения доходов населения и участия в социальных программах в 2017 году, утвержденными приказом Росстата от 30.08.2016 № 452 [8], и другими нормативными правовыми актами не установлены в национальном определении понятия «национальная черта бедности» (необходимо для сбора данных по показателю 1.2.1.) или «нищета» (необходимо для сбора данных по показателю 1.2.2.).

При этом, если под «национальной чертой бедности» подразумевать уровень жизни, при котором среднедушевой располагаемый доход (располагаемый доход) ниже величины прожиточного минимума, установленного в соответствующем субъекте Российской Федерации, который для каждого субъекта Российской Федерации свой, то итоги 
Выборочного наблюдения можно использовать для сбора данных по показателю 1.2.1. в разрезе субъектов Российской Федерации. Однако данные в целом по Российской Федерации (или по Федеральным округам) будут несопоставимы именно по причине разного уровня величины прожиточного минимума для разных субъектов Российской Федерации.

Ряд российских исследователей (Тихонова и Мареева, 2016) [9] отмечают различия в восприятии бедности по субъектам РФ. Они отмечают, что оценка россиянами уровня бедности зависит от региона и места жительства. Взаимосвязь между субъективным порогом бедности и официальным прожиточным минимумом является слабой. Это объясняется тем, что прожиточный минимум определяется региональными властями самостоятельно, с учетом их экономических ресурсов и политических приоритетов. В результате изменения прожиточных минимумов между регионами значительны, даже для регионов с аналогичными характеристиками уровня жизни и типа расселения и т. д.

Ряд других исследователей (Бурдяк и Попова. 2007) [10] используют данные Ленинградской области для сравнения абсолютной, относительной и субъективной бедности. Их исследование показывает, что абсолютная бедность характерна для семей с детьми, а относительная и субъективная бедность более распространена среди пенсионеров. По их оценкам, бедность ребенка зависит прежде всего от доходов родителей, а также от межсемейных денежных трансфертов, страховых выплат и пенсий. Демографическая структура семьи, образование родителей и их позиции на рынке труда также оказывают влияние на детскую бедность, но в меньшей степени.

Большинство стран в основном измеряют имущество с помощью данных о доходах, данных о расходах или их комбинации. Способность тратить в первую очередь определяется доходом. Но расходы и доходы не идентичны, поскольку домохозяйства также заимствуют, продают активы или используют сбережения, когда их доход низок. И наоборот, домохозяйства часто экономят, когда время особенно благоприятно. Измерение бедности как дефицита в расходах учитывает такие виды механизмов преодоления и общие возможности домашних хозяйств сглаживать потребление с течением времени.

Обычно следующим шагом является определение черты бедности. Черта бедности обычно определяет доход (или уровень расходов), необходимый для покупки связки основных товаров (как правило, продукты питания, одежда, жилье, вода, электричество, школьное образование и надежное здравоохранение). Определение бедноты как бедноты с доходами (или расходами) ниже заданной линии вносит ясность и целенаправленность в процесс разработки и анализа политики. Наличие черты бедности позволяет экспертам подсчитывать бедные слои населения, целевые ресурсы и следить за прогрессом в соответствии с четким ориентиром. Информирование о масштабах нищеты становится проще, а разъяснение понятия лишений-проще.

Базовый подход начинается с порога питания, выбранного для отражения минимальных потребностей в здоровой жизни, и затем вносятся коррективы в отношении непродовольственных расходов (например, на жилье и одежду). Чтобы установить черту бедности, статистики, как правило, определяют корзину продуктов питания, которая обеспечит минимальные потребности в питании. При этом стоимость корзины продуктов определяется действующими статистическими инструментами из форм федерального статистического наблюдения, которые связаны со значительными временными и финансовыми издержками.

Для повышения точности и снижения расходов на сбор данных о ценах товаров, включенных в продовольственную корзину, мы предлагаем использовать более современные технологии, например, данные (big data), которые получает Федеральная налоговая служба России в результате введения технологий «интернета вещей» (системы On-line касс) в розничной торговле, а также данные о транзакциях с кредитных (дебетовых) карт по данным товарным группам и/или данные платформ электронной коммерции (яндекс.маркет и т.п.). Представляется, что медианные значения по данным 
источникам информации будут более точны и актуальны для определения реальной стоимости «продовольственной корзины».

Существенные проблемы также связаны с использованием итогов Выборочного наблюдения доходов населения и участия в социальных программах для сбора данных по показателю 1.2.2. (Доля мужчин, женщин и детей всех возрастов, живущих в нищете во всех ее проявлениях, согласно национальным определениям). В связи с отсутствием понятия «нищета», итоги этого Выборочного наблюдения для сбора данных по этому показателю ЦУР в настоящее время использовать нельзя. В этой части методология Выборочного наблюдения также нуждается в совершенствовании.

Для показателя 1.3.1. (Доля населения, охватываемого минимальным уровнем/ системами социальной защиты, в разбивке по полу, с выделением детей, безработных, пожилых, инвалидов, беременных, новорожденных, лиц, получивших трудовое увечье, бедных и уязвимых) в настоящее время планируется использовать данные из указанного Выборочного наблюдения, если считать, что семья (одиноко проживающий гражданин), среднедушевой доход которой (доход которого) ниже величины прожиточного минимума, считается малоимущей (малоимущим) и только в этом случае имеет право на получение социальной поддержки (статья 6 Федерального закона от 24 октября 1997 г. № 134-Ф3 «О прожиточном минимуме в Российской Федерации») [11].

Однако за последние годы в России для целей использования в бюджетном процессе сформирован реестр получателей социальной помощи и именно его данные представляются более точными для получения значений для данного показателя ЦУР без проведения соответствующего выборочного наблюдения.

С учетом предложенных выше изменений в методологии формирования и новых источниках данных по показателям ЦУР возможно разработать алгоритмы, основанные с одной стороны на методологии международных организаций - координаторов показателей ЦУР, с другой стороны, на основе новых источников данных, а также провести экспериментальные расчеты показателей ЦУР на основе этих новых источников данных для формирования более точной и актуальной эмпирической базы в целом по России и по субъектам Российской Федерации.

Далее необходимо провести экспериментальные расчеты показателей ЦУР на основе на основе новых источников данных для формирования эмпирической базы по указанным выше показателям ЦУР.

В качестве новых источников данных по ряду показателей ЦУР возможно также рассмотреть возможность использования данных выборочных обследований по социальнодемографическим проблемам в социальных сетях (vk.com, Facebook, ok.ru и др.).

На основе этой эмпирической базы предлагается также провести экспериментальные расчеты показателей ЦУР и сравнить их с экспериментальными расчетами показателей ЦУР на основе имеющейся в Росстате эмпирической базы.

В результате этих работ могут быть получены более систематизированные материалы по методам формирования показателей ЦУР, приведенным в методологии международных организаций, организаций - координаторов показателей ЦУР, алгоритмы их расчета и результаты экспериментальных расчетов на основе на основе новых источников наблюдений для формирования эмпирической базы по показателям уровня бедности.

Для обоснования наиболее рациональных и оптимальных условий размещения установленного перечня вопросов по конкретным программам выборочных обследований по социально-демографическим проблемам с учетом их тематики, периодичности, размеров выборочных совокупностей и содержательной емкости новых выборочных наблюдений и обследований, необходимых для получения данных по показателям ЦУР в том числе в социальных сетях, а также из действующих реестров и регистров, с учетом:

- тематики (доходы населения, участие в социальных программах, условия жизни населения, включая водоснабжение, рацион питания населения, использование суточного фонда времени населением и др.); 
- периодичности (например, синхронизации проведения выборочных наблюдений и обследований со сроками и периодичностью проведения добровольных национальных обзоров показателей ЦУР по странам);

- размеров выборочных совокупностей и содержательной емкости, включая определение примерных затрат на расчет показателей ЦУР в России (обоснование бюджетных ассигнований, которые могут понадобится для проведения соответствующих выборочных наблюдений и обследований по показателям ЦУР, в том числе в сравнении с расходами на проведение соответствующих выборочных наблюдений и обследований в социальных сетях).

Таким образом по результатам анализа состава показателей целей устойчивого развития ООН, действующих источников и методологии сбора данных предлагается использовать данные обследований в социальных сетях, данные действующих реестров и регистров, а также альтернативные цифровые источники данных о ценах товаров, включаемых в потребительскую корзину, для измерения ряда показателей целей устойчивого развития ООН по России.

\section{Литература}

[1] Цели в области устойчивого развития / OOH. URL: https://www.un.org/sustainabledevelopment/ru/sustainable-development-goals/ (дата обращения 15.03.2019).

[2] Sustainable Development Goals (SDGs) and The 2030 Agenda / World Bank. URL: http://www.worldbank.org/en/programs/sdgs-2030-agenda (дата обращения 15.03.2019).

[3] Decent work and the 2030 Agenda for sustainable development / International Labour Organization. URL: https://www.ilo.org/global/topics/sdg-2030/lang--en/index.htm (дата обращения 15.03.2019).

[4] Цели в области устойчивого развития / Продовольственная и сельскохозяйственная организация ОOH. URL: http://www.fao.org/sustainable-development-goals/ru/ (дата обращения 15.03.2019).

[5] Цели устойчивого развития (ЦУР) / Всемирная организация здравоохранения. URL: https://www.who.int/topics/sustainable-development-goals/ru/ (дата обращения 15.03.2019).

[6] Егоренко С. Мониторинг показателей целей устойчивого развития [презентация, 30.11.2017] / Росстат. URL: http://www.gks.ru/publish/cur/s1/egorenko.pdf (дата обращения 15.03.2019).

[7] Постановление Правительства РФ от 27 ноября 2010 г. № 946 «Об организации в Российской Федерации системы федеральных статистических наблюдений по социально-демографическим проблемам и мониторинга экономических потерь от смертности, заболеваемости и инвалидизации населения».

[8] Приказ Росстата от 30.08.2016 № 452 «Об утверждении Указаний по подготовке и проведению Выборочного наблюдения доходов населения и участия в социальных программах».

[9] Мареева С.В., Тихонова Н.Е. Бедность и социальные неравенства в России в общественном сознании // Мир России. 2016. Т. 25, № 2. С. 37-67.

[10]Бурдяк А.Я., Попова Д.О. Причины бедности семей с детьми: по результатам обследования домохозяйств Ленинградской области. СПЭРО, 2007.

[11]Федеральный закон от 24 октября 1997 г. № 134-Ф3 «О прожиточном минимуме в Российской Федерации». 


\title{
Digital Economy and Quality of Living Indicators
}

\author{
O.V. Alexandrov \\ CEFC Group
}

Implementing new international initiatives aimed at developing innovative instruments for collecting statistical data for measuring sustainable societal development requires designing methodologies and broadening the range of data sources used for constructing quality of living indicators. The article reviews the list of the UN sustainable development indicators, the existing data sources and the methodology of data collection and suggests to use surveys in social media, data of official registers, and alternative data sources on prices of products included in the minimal product sample to measure some of the UN sustainable development indicators in Russia.

Keywords: sustainable development goals, poverty, social media, indicators

Reference for citation: Alexandrov O.V. Digital Economy and Quality of Living Indicators // The State and Citizens in the Electronic Environment. Vol. 3 (Proceedings of the XXII International Joint Scientific Conference «Internet and Modern Society», IMS-2019, St. Petersburg, June 19-22, 2019). - St. Petersburg: ITMO University, 2019. P. 25 - 34. DOI: 10.17586/2541-979X-2019-3-25-34

\section{Reference}

[1] The Sustainable Development Goals / United Nations. URL: https://www.un.org/sustainabledevelopment/ru/sustainable-development-goals/ (access date 15.03.2019). (In Russian)

[2] Sustainable Development Goals (SDGs) and The 2030 Agenda / World Bank. URL: http://www.worldbank.org/en/programs/sdgs-2030-agenda (access date 15.03.2019).

[3] Decent work and the 2030 Agenda for sustainable development / International Labour Organization. URL: https://www.ilo.org/global/topics/sdg-2030/lang--en/index.htm (access date 15.03.2019).

[4] The Sustainable Development Goals / FAO. URL: http://www.fao.org/sustainabledevelopment-goals/ru/ (access date 15.03.2019). (In Russian)

[5] Sustainable Development Goals (SDGs) / WHO URL: https://www.who.int/topics/ sustainable-development-goals/ru/ (access date 15.03.2019). (In Russian)

[6] Egorenko S. Monitoring pokazateley tseley ustoychivogo razvitiya. URL: http://www.gks.ru/publish/cur/s1/egorenko.pdf (access date 15.03.2019). (In Russian)

[7] Postanovlenie Pravitel'stva RF ot 27 nojabrja 2010 g. № 946 «Ob organizacii v Rossijskoj Federacii sistemy federal'nyh statisticheskih nabljudenij po social'no-demograficheskim problemam i monitoringa jekonomicheskih poter' ot smertnosti, zabolevaemosti i invalidizacii naselenija». (In Russian)

[8] Prikaz Rosstata ot 30.08.2016 № 452 «Ob utverzhdenii Ukazanij po podgotovke i provedeniju Vyborochnogo nabljudenija dohodov naselenija i uchastija $\mathrm{v}$ social'nyh programmah». (In Russian)

[9] Mareeva S.V., Tihonova N.E. Bednost' i social'nye neravenstva v Rossii v obshhestvennom soznanii [Public Perceptions of Poverty and Social Inequality in Russia] // Mir Rossii. 2016. Vol. 25, № 2. P. 37-67. (In Russian)

[10] Burdjak A.Ja., Popova D.O. Prichiny bednosti semej s det'mi: po rezul'tatam obsledovanija domohozjajstv Leningradskoj oblasti. SPJeRO, 2007. (In Russian)

[11]Federal'nyj zakon ot 24 oktjabrja 1997 g. № 134-FZ «O prozhitochnom minimume v Rossijskoj Federacii». (In Russian) 